\title{
Deregulation of the IL-1 $\beta$ axis in chronic recurrent multifocal osteomyelitis
}

\author{
Roberta Scianaro', Antonella Insalaco', Luisa Bracci Laudiero', Rita De Vito², Marco Pezzullo ${ }^{3}$, Anna Teti', \\ Fabrizio De Benedetti ${ }^{1 *}$ and Giusi Prencipe ${ }^{1}$
}

\begin{abstract}
Background: This study aims to investigate the inflammasome response in peripheral blood mononuclear cells (PBMCs) and the expression of inflammasome components in bone biopsies from patients with chronic recurrent multifocal osteomyelitis (CRMO).

Methods: The expression of inflammasome components mRNAs was evaluated in PBMCs isolated from 15 CRMO patients and 13 healthy controls by quantitative real-time PCR. The Interleukin (IL)-1 $\beta$ released in the medium of PBMC cultures after treatment with lipopolysaccharides (LPS) alone or LPS and ATP was measured by ELISA. Immunohistochemical staining for Apoptosis-associated Speck-like protein (ASC), caspase-1 (CASP-1), Nod-like receptor protein-3 (NLRP3) and IL-1 $\beta$ expression was performed in bone biopsies from CRMO patients.

Results: mRNA levels of ASC, CASP-1 and IL-1 $\beta$ were significantly higher in freshly isolated PBMCs from CRMO patients in active disease than in healthy controls. CASP-1 and IL-1 $\beta$ transcript levels were significantly higher also in PBMCs from CRMO patients in remission compared to healthy controls. PBMCs from CRMO patients in active disease stimulated in vitro with LPS showed a significant increase in IL-1 $\beta$ release compared to healthy control cells. Immunohistochemistry staining of bone tissue revealed the expression of inflammasome components in CRMO osteoclasts.
\end{abstract}

Conclusions: Our data suggest that an abnormal regulation of IL-1 $\beta$ axis may be involved in CRMO pathogenesis.

Keywords: Chronic recurrent multifocal osteomyelitis, Autoinflammatory disorders, Inflammasome, Interleukin-1 $\beta$, Osteoclasts

\section{Background}

Chronic recurrent multifocal osteomyelitis (CRMO) is a rare skeletal disorder, predominantly affecting children, that presents with bone pain, fever and sterile multifocal osteolytic bone lesions, characterized by inflammatory infiltrate and activated osteoclasts [1].

Osteoclasts belong to the monocyte-macrophage lineage, are responsible for bone resorption and are regulated by pro-inflammatory cytokines [2]. CRMO is usually sporadic, but there is evidence of a genetic component, as several reports described the disease in siblings and in monozygotic twins [3]. Moreover, a monogenic disease associated with CRMO, termed Majeed's Syndrome, is known [4].

\footnotetext{
* Correspondence: fabrizio.debenedetti@opbg.net

'Rheumatology Unit, Bambino Gesù Children's Hospital, Rome, Italy

Full list of author information is available at the end of the article
}

Although CRMO is considered an autoinflammatory disease, the pathogenetic mechanisms are still unknown. Recent findings demonstrate, in a murine model of CRMO, an inflammasome-independent role for the interleukin-1 (IL-1) pathway in the disease pathogenesis [5]. In patients with CRMO, an imbalance between pro-inflammatory (IL-6, TNF- $\alpha$ ) and anti-inflammatory cytokines (IL-10) has been hypothesized to be involved [6]. Autoinflammatory diseases are characterized by deregulation of the innate immune system, often involving the IL-1 $\beta$ pathway [7]. Release of IL-1 $\beta$ is induced by inflammasomes, multiprotein cytoplasmic complexes, composed by pattern recognition receptors, including Toll-like receptors (TLRs) and Nod-like receptors, the adaptor protein Apoptosisassociated speck-like protein containing a CARD (ASC) and pro-caspase-1, that sense microbial molecules and endogenous danger signals [8]. 
IL-1 $\beta$ secretion requires two signals. The first signal is provided by microbial or endogenous molecules that activate NF- $\mathrm{kB}$ and induce, through a TLR, expression and synthesis of the inactive IL-1 $\beta$ precursor (pro-IL-1 $\beta$ ). The second signal is provided by adenosine triphosphate (ATP), certain bacterial toxins or particulate matter and directly activates inflammasomes, resulting in pro-IL-1 $\beta$ cleavage and IL-1 $\beta$ secretion [8].

The aim of this study was to examine the inflammasome response in peripheral blood mononuclear cells (PBMCs) and the expression of inflammasome components in bone biopsies from CRMO patients.

\section{Methods}

\section{Subjects}

Peripheral blood was obtained from 15 patients with CRMO. The diagnosis of CRMO was based on clinical presentation, laboratory and imaging data and bone biopsy. Bone biopsies (obtained from all patients, except one) showed evidence of sterile bone inflammation.

At the time of the study, 7 patients had active disease, defined by patients' reported bone and/or joint pain, increased C-reactive protein (CRP) (normal $<0.5 \mathrm{mg} / \mathrm{dl}$ ) or erythrocyte sedimentation rate (ESR) (normal $<20 \mathrm{~mm} / \mathrm{h}$ ) and lesions demonstrating increased uptake of technetium-99 $\mathrm{m}$ in bone scan. The main characteristics of CRMO patients in active disease were: 5 females and 2 males, mean age at onset $9.57 \pm 5.16$ years, mean age at sampling $10.31 \pm$ 5.72 years, number of bone lesions from 1 to 6 (median 3); 5 patients were treated with non steroidal anti-inflammatory drugs (NSAID) and 2 were not receiving any treatment. The remaining 8 patients who did not meet the criteria for active disease were defined as having remission: 4 females and 4 males, mean age at onset 7.22 \pm 4.64 years, mean age at sampling $10.36 \pm 5.38$ years; 2 patients were treated with methotrexate, 1 with sulfasalazine and NSAID and the remaining 5 were not receiving any treatment.

Thirteen healthy children comparable for age, hospitalized for minor surgical procedures, were used as controls. Blood samples were collected before they underwent surgery. They did not have evidence of infection or inflammation or increased CRP at time of blood sampling. In addition, peripheral blood was obtained also from 7 children with active juvenile idiopathic arthritis (JIA) (mean age at sampling $8.14 \pm 2.54$ years). Blood samples were taken after informed consent of the parents.

The study was approved by the Institutional Ethical Committee.

\section{PBMC isolation and in vitro stimulation}

PBMCs were separated from blood by Ficoll/Histopaque (Sigma-Aldrich). Freshly isolated PBMCs were incubated in DMEM (Gibco) plus 10\% FBS with $10 \mathrm{ng} / \mathrm{ml}$ lipopolysaccharides (LPS, E. coli serotype 055:B5, Sigma-Aldrich) for 3 hours, or stimulated with $10 \mathrm{ng} / \mathrm{ml}$ LPS for 2 hours, followed by stimulation with $2 \mathrm{mM}$ ATP (Sigma-Aldrich) for 1 hour.

\section{Cytokine detection}

Levels of IL-1 $\beta$ in PBMC supernatants were quantified by ELISA (R\&D System). Circulating IL-1 $\beta$ and IL-6 levels were measured in plasma collected from patients and controls by ELISA, using commercial kits (R\&D System) according to the manufacturer's instructions.

\section{RNA isolation and real-time PCR}

Total RNA was extracted using the Qiagen-RNeasy Mini kit (Qiagen) from $10^{6}$ PBMCs and cDNA was obtained using the Superscript Vilo kit (Invitrogen). Real-time PCR assays were performed using TaqMan Universal PCR Master mix (Applied Biosystems) and the following gene-expression assays: human $I L-1 \beta, T N F-\alpha, C A S P-1$, $A S C$ and NLRP3 (Applied Biosystem). Gene expression data were normalized using HPRT, as endogenous control. Data are expressed as arbitrary units (AU) using the $2^{-\Delta \mathrm{Ct}}$ transformation method.

\section{Immunohistochemistry}

Bone-biopsy specimens were available from three CRMO patients and were evaluated by immunohistochemistry. A bone-biopsy from a patient with acute lymphoblastic leukemia in remission was used as tissue control. Formalin-fixed, decalcified and embedded in paraffin bone-biopsy specimens were immunostained with antibodies to human ASC (LifeSpan BioSciences), NLRP3 (Sigma-Aldrich), CASP-1 (Cell Signaling), IL-1 $\beta$ (Cell Signaling) and IL-6 (Abcam), revealed by LSAB2 System-HRP (DakoCytomation) and counterstained with hematoxylin.

\section{Statistical analysis}

Quantitative data were expressed as mean \pm SD or as median and interquartile range (IQR). Statistical analysis was performed by the Mann-Whitney $U$ test. $P$ values less than 0.05 were considered significant.

\section{Results}

$A S C, C A S P-1$ and $I L-1 \beta$ mRNA levels were significantly higher in PBMCs freshly isolated from CRMO patients during active disease compared to PBMCs from healthy controls. The mRNA expression of CASP-1 and $I L-1 \beta$ was also significantly higher in PBMCs from patients in remission compared to healthy controls (Figure 1A-D).

No significant difference in TNF- $\alpha$ expression was observed between the two patient groups and healthy controls (Figure 1E). 

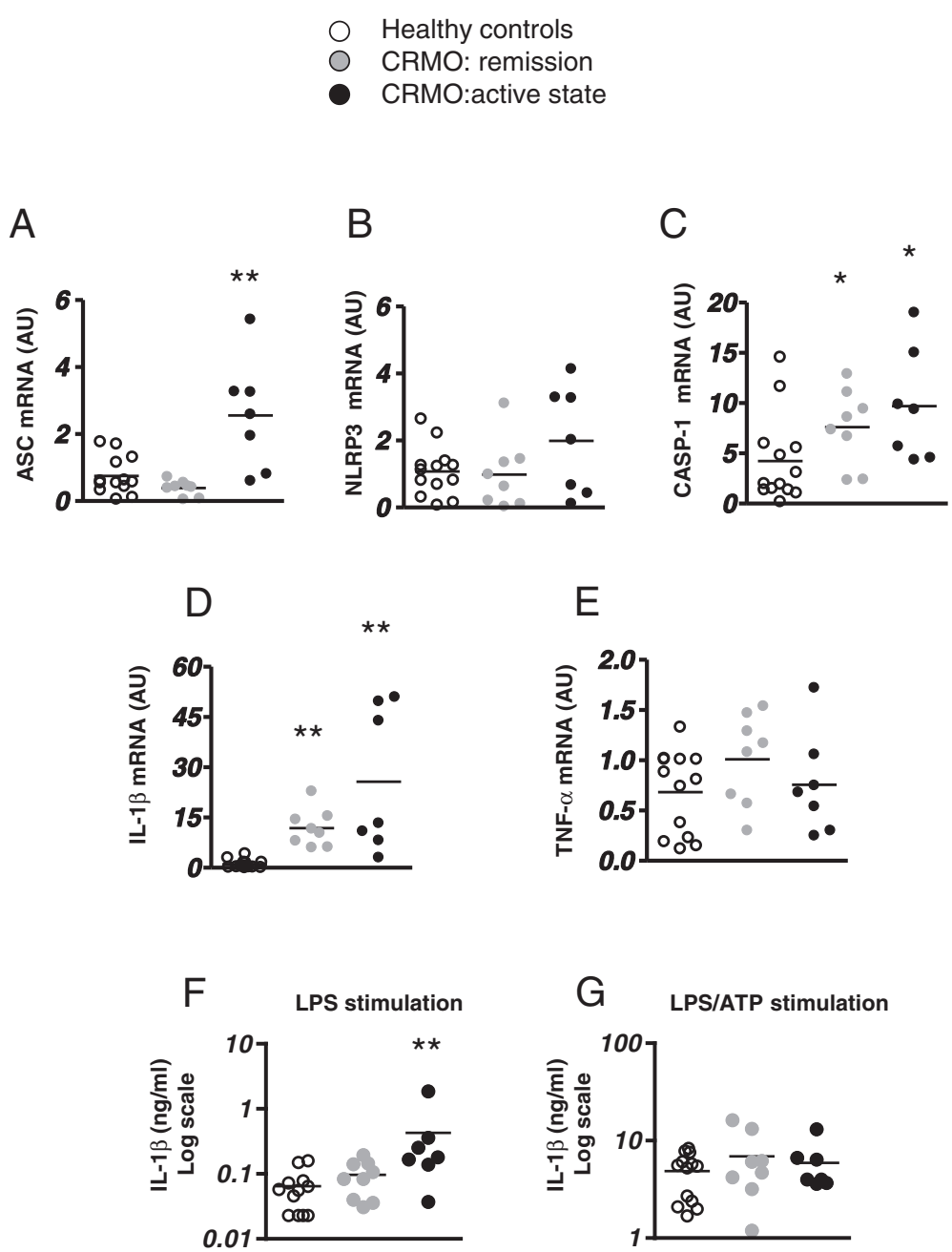

Figure 1 Characterization of PBMCs from CRMO patients. (A-E) Real Time-PCR analysis of gene products involved in the regulation of IL-1 $\beta$, including ASC, NLRP3, CASP-1, IL-1 $\beta$ and of the pro-inflammatory cytokine TNF- $a$ in freshly isolated PBMCs obtained from CRMO patients in remission (gray dots) or with active disease (black dots) and healthy controls (white dots). Values are presented as arbitrary unit (AU). (F-G) IL-1 $\beta$ released in supernatants by PBMCs isolated from CRMO patients in remission or in active disease and from healthy controls, after stimulation with $10 \mathrm{ng} / \mathrm{ml}$ LPS for 3 hours (F) or $10 \mathrm{ng} / \mathrm{ml}$ LPS for 2 hours followed by treatment with $2 \mathrm{mM}$ ATP for 1 hour (G). IL-1 $\beta$ was measured by ELISA. Black lines represent the mean value. ${ }^{*} p<0.05,{ }^{* *} p<0.01$ vs healthy controls.

When we analyzed cytokine levels in plasma, we failed to measure detectable levels of circulating IL-1 $\beta$ (data not shown). We found that, compared to healthy controls [median value $0.156 \mathrm{pg} / \mathrm{ml}$, Interquartile range (IQR) 0.156-0.612], circulating levels of IL-6 were similar in patients in remission (median value $0.327 \mathrm{pg} / \mathrm{ml}, \mathrm{IQR}$ $0.156-1.825)(\mathrm{p}=0.14)$, while they were significantly increased in patients during active disease (median value $8.48 \mathrm{pg} / \mathrm{ml}$, IQR 4.93-23.72) ( $\mathrm{p}=0.0004)$.

To evaluate inflammasome activation in PBMCs from CRMO patients, freshly isolated PBMCs were stimulated in vitro with LPS alone or LPS plus ATP and the IL-1 $\beta$ released in the medium was measured. After LPS stimulation, the amount of IL-1 $\beta$ released by PBMCs from CRMO patients with active disease was significantly higher when compared to patients during remission or to healthy controls (Figure 1F). In contrast, cells from patients with active JIA stimulated with LPS alone produced amount of IL-1 $\beta$ comparable to those released by healthy controls $(0.067 \mathrm{ng} / \mathrm{ml} \pm 0.061$ versus $0.064 \mathrm{ng} / \mathrm{ml} \pm 0.046$, $\mathrm{p}>0.5$ ). Stimulation with LPS plus ATP led, as expected, to a marked increase in IL- $1 \beta$ release, with no significant differences between the three groups (Figure 1G). In patients with active disease, $I L-1 \beta$ mRNA levels in PBMCs freshly isolated or IL-1 $\beta$ release following in vitro LPS stimulation were not significantly associated with the number of bone lesions $(\mathrm{R}=0.480, \mathrm{p}=0.27 ; \mathrm{R}=0.566$, $\mathrm{p}=0.17$, respectively) or $\operatorname{ESR}(\mathrm{R}=0.141, \mathrm{p}=0.75 ; \mathrm{R}=0.50$, $\mathrm{p}=0.24$, respectively). In two patients, we analyzed PBMC $I L-1 \beta$ mRNA levels before and after (16 and 18 days, 
respectively) pamidronate administration: a 2-fold reduction in $I L-1 \beta$ mRNA levels was observed (pre-treatment 49.7 and 50.9; post-treatment 28.1 and 23.3 arbitrary unit, respectively).

The presence of activated osteoclasts is a typical feature of bone lesions in CRMO. Because of their potential pathogenic role in CRMO, we performed the immunohistochemical staining of bone biopsy specimens from CRMO patients $(n=3)$, (Figure $2 A^{I}-F^{I}$ ) and from one tissue control (Figure $2 \mathrm{~A}-\mathrm{F}$ ) with antibodies to ASC, NLRP3, CASP-1 and IL-1 $\beta$. In bone tissue from CRMO patients and one control, the expression of the
A

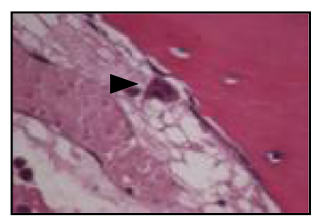

B

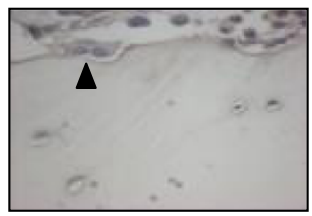

C

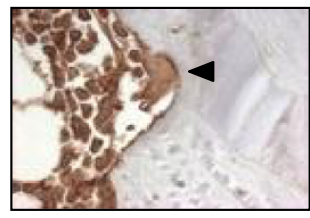

D

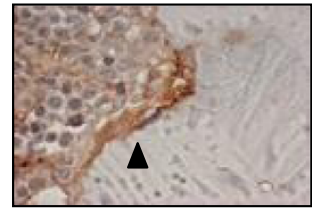

E

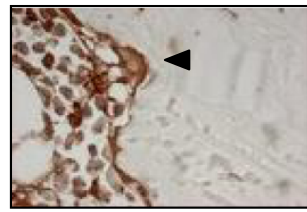

F

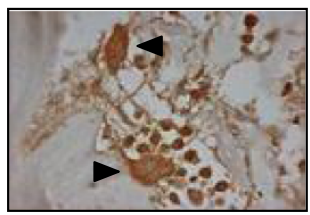

G

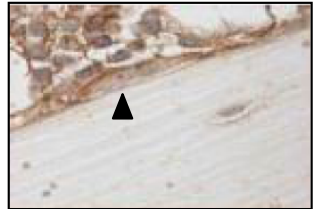

Control
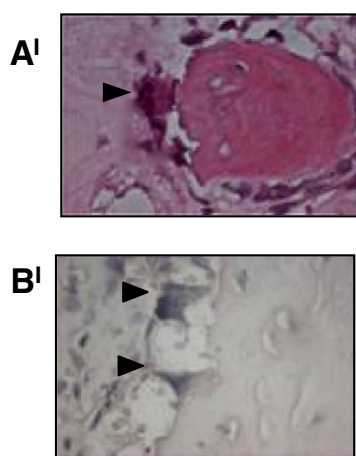

$\mathrm{C}^{\prime}$

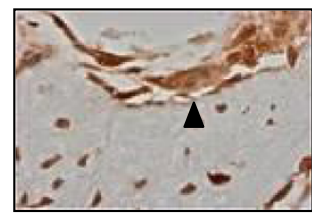

$D^{1}$

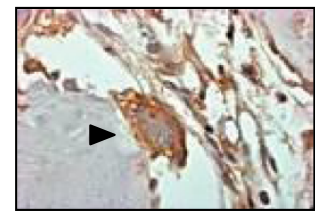

E'
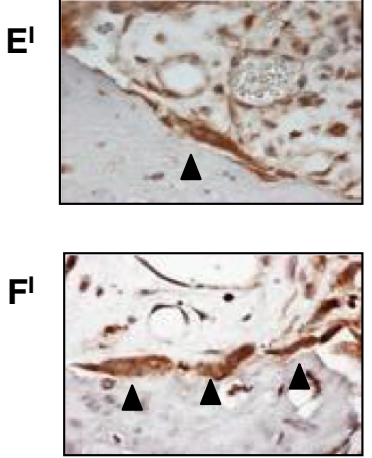

G'

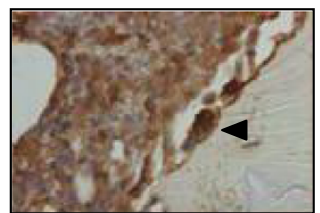

CRMO
H-E

Control antibody

ASC

NLRP3

CASP-1

IL-1 $\beta$

IL-6

Figure 2 Expression of inflammasome components and IL- 6 in bone biopsies from CRMO patients and from one tissue control.

Representative immunohistochemical staining of decalcified human bone biopsy specimens from a tissue control (A-B-C-D-E-F-G) and patients with CRMO (A'-B'-C'-D'-E'-F'-G'). Bone sections were stained with hematoxylin-eosin, a secondary antibody only or with primary antibodies as indicated. Magnification: X63. Arrows: osteoclasts. 
three inflammasome components as well as of IL-1 $\beta$ was detected, demonstrating that also osteoclasts expressed components of the inflammasome machinery.

\section{Discussion}

We demonstrated an abnormal regulation of the IL-1 $\beta$ axis and its secretory machinery in CRMO patients. PBMCs from CRMO patients obtained during the active disease expressed higher mRNA levels of inflammasome key components, $A S C$ and $C A S P-1$, and higher levels of $I L-1 \beta$ mRNA. Moreover, PBMCs from CRMO patients, cultured in vitro, showed a higher IL-1 $\beta$ release after treatment with LPS alone. These results are consistent with a deregulation of the IL- $1 \beta$ processing machinery. Indeed, in patients with cryopyrinopathies, caused by gain of function NLPR3-mutations, increased IL-1 $\beta$ release following stimulation with LPS alone is a typical feature of the disease [9]. IL-1 $\beta$ release can result in autocrine stimulation and in the secondary induction of other cytokines, such as IL-6. We indeed found that high circulating IL-6 levels are present during active disease. In vivo, neutralization of excessive IL- $1 \beta$ in cryopyrinopathies and in deficiency of interleukin-1 receptor antagonist (DIRA) results in decrease in IL-6 production [10-12].

We could not detect circulating IL-1 $\beta$. However, detection of circulating IL-1 $\beta$ has proven to be extremely difficult even in diseases in which undoubtedly excessive IL-1 $\beta$ production is known to be involved, including cryopirinopathies and systemic JIA [13,14]. Therefore, the absence of detectable levels of IL-1 $\beta$ does not rule out a pathogenic role for this cytokine. Indeed, satisfactory responses to anakinra have been reported in one patient with synovitis-acne-pustulosis-hyperostosis-osteitis syndrome (SAPHO) [15], and in two patients with Majeed syndrome [16]. One transient response has been reported in one patient with CRMO [17]. These observations, together with our results, point to a role for IL- $1 \beta$ in the pathogenesis of CRMO and further support the inclusion of CRMO in the group of autoinflammatory diseases. The higher mRNA levels of CASP-1 and pro-IL-1 $\beta$ found in patients during remission suggest the presence of a sustained proinflammatory state in CRMO patients. The mechanisms leading to this proinflammatory state, as well to activation of the inflammasome in vitro hyper-response are unknown: in particular, possible contribution of genetics have remained unclarified. In addition, we found high expression of IL-6 in bone biopsies from CRMO patients (Figure $2 \mathrm{G}^{\mathrm{I}}$ ), suggesting that IL-6 produced at inflammatory sites may be the source of the circulating measurable cytokine in the blood. Circulating IL-6 levels were significantly higher in CRMO patients during active disease. In cryopirinopathies, in which abnormal IL-1 secretion drives the cytokine cascade and all clinical and laboratory features, IL-6 production in tissues and high circulating levels have been shown to be completely IL-1 $\beta$ dependent $[10,18]$.

We have also shown that osteoclasts in vivo express inflammasome-related proteins. This is consistent with data in the literature [19-21] and a publically available expression profile database, showing detectable mRNA levels of inflammasome components in osteoclasts differentiated in vitro [22]. However, the function of the inflammasome in osteoclasts is not known yet. In this respect, future studies in osteoclasts from patients with Majeed syndrome might represent the ideal model to investigate, in the context of a genetic abnormality, the presence of abnormal function of the osteoclasts.

\section{Conclusions}

We have shown increased IL-1 $\beta$ secretion by peripheral blood mononuclear cells of CRMO patients during active disease and expression of inflammasome components by CRMO and control osteoclasts in vivo. These results further support a role for autoinflammation in CRMO.

\section{Abbreviations \\ CRMO: Chronic recurrent multifocal osteomyelitis; PBMCs: Peripheral blood mononuclear cells; IL: Interleukin; TLR: Toll-like receptor; \\ LPS: Lipopolysaccharides; ASC: Apoptosis-associated Speck-like protein containing a CARD; CASP-1: Caspase-1; NLRP3: Nod-like receptor protein-3; ATP: Adenosine triphosphate; CRP: C-reactive protein; NSAID: Non steroidal anti-inflammatory drugs; ESR: Erythrocyte sedimentation rate; DIRA: Deficiency of interleukin-1 receptor antagonist; SAPHO: Synovitis-acne-pustulosis- hyperostosis-osteitis syndrome; JIA: Juvenile idiopathic arthritis.}

\section{Competing interests}

The authors have declared no conflicts of interest.

\section{Authors' contributions}

All authors were involved in the design of the study. RS performed stimulation of PBMCs ex vivo, cytokine measurement by ELISA, Real-time PCR analyses and drafted the manuscript, under the supervision and with the collaboration of GP. Al was responsible for the collection of data and provided statistical analysis of the data. RDV and MP were responsible for Immunohistochemical analyses. LBL and AT contributed to the study design and analysis and interpretation of the data. FDB and GP conceived the study, oversaw the project and critically reviewed the manuscript. All the authors have contributed to the writing of the manuscript and have seen and approved the final version of the manuscript.

\section{Author details}

${ }^{1}$ Rheumatology Unit, Bambino Gesù Children's Hospital, Rome, Italy. ${ }^{2}$ Division of Pathology, Bambino Gesù Children's Hospital, Rome, Italy. ${ }^{3}$ Core Facilities, Bambino Gesù Children's Hospital, Rome, Italy. ${ }^{4}$ Department of

Biotechnological and Applied Clinical Sciences, University of L'Aquila, L'Aquila, Italy.

Received: 6 December 2013 Accepted: 3 July 2014 Published: 17 July 2014

\section{References}

1. Giedion AHW, Masel LF, Vischer D: [Subacute and chronic "symmetrical" osteomyelitis]. Ann Radiol (Paris) 1972, 15(3):329-342.

2. Del Fattore A, Teti A: The tight relationship between osteoclasts and the immune system. Inflamm Allergy Drug Targets 2012, 11:181-187.

3. Ferguson PJ, El-Shanti HI: Autoinflammatory bone disorders. Curr Opin Rheumatol 2007, 19(5):492-498. 
4. Ferguson PJ, Chen S, Tayeh MK, Ochoa L, Leal SM, Pelet A, Munnich A, Lyonnet S, Majeed HA, El-Shanti H: Homozygous mutations in LPIN2 are responsible for the syndrome of chronic recurrent multifocal osteomyelitis and congenital dyserythropoietic anaemia (Majeed syndrome). J Med Genet 2005, 42(7):551-557.

5. Cassel SL, Janczy JR, Bing X, Wilson SP, Olivier AK, Otero JE, Iwakura Y, Shayakhmetov DM, Bassuk AG, Abu-Amer Y, Brogden KA, Burns TL, Sutterwala FS, Ferguson PJ: Inflammasome-independent IL-1 $\beta$ mediatesutoinflammatory disease in Pstpip2-deficient mice. Proc Natl Acad Sci U S A 2014, 111(3):1072-1077.

6. Hofmann SR, Schwarz T, Möller JC, Morbach H, Schnabel A, Rösen-Wolff A, Girschick HJ, Hedrich CM: Chronic non-bacterial osteomyelitis is associated with impaired Sp1 signaling, reduced IL10 promoter phosphorylation, and reduced myeloid IL-10 expression. Clin Immunol 2011, 11:317-327.

7. Lachmann HJ, Quartier P, So A, Hawkins PN: The emerging role of interleukin-1 beta in autoinflammatory diseases. Arthritis Rheum 2011, 63:314-324

8. Rathinam VA, Vanaja SK, Fitzgerald KA: Regulation of inflammasome signaling. Nat Immunol 2012, 13:333-342.

9. Gattorno M, Tassi S, Carta S, Delfino L, Ferlito F, Pelagatti MA, D'Osualdo A Buoncompagni A, Alpigiani MG, Alessio M, Martini A, Rubartelli A: Pattern of interleukin-1 beta secretion in response to lipopolysaccharide and ATP before and after interleukin-1 blockade in patients with CIAS1 mutations. Arthritis Rheum 2007, 56(9):3138-3148.

10. Goldbach-Mansky R, Dailey NJ, Canna SW, Gelabert A, Jones J, Rubin BI, Kim HJ, Brewer C, Zalewski C, Wiggs E, Hill S, Turner ML, Karp Bl, Aksentijevich I, Pucino F, Penzak SR, Haverkamp MH, Stein L, Adams BS, Moore TL, Fuhlbrigge RC, Shaham B, Jarvis JN, O'Neil K, Vehe RK, Beitz LO, Gardner G, Hannan WP, Warren RW, Horn W, et al: Neonatal-onset multisystem inflammatory disease responsive to interleukin-1 beta inhibition. N Engl J Med 2006, 355(6):581-592.

11. Rosengren S, Mueller JL, Anderson JP, Niehaus BL, Misaghi A, Anderson S, Boyle DL, Hoffmann HM: Monocytes from familial cold autoinflammatory syndrome patients are activated by mild hypothermia. J Allergy Clin Immunol 2007, 119(4):991-996.

12. Aksentijevich I, Masters SL, Ferguson PJ, Dancey P, Frenkel J, Van RoyenKerkhoff A, Laxer R, Tedgård U, Cowen EW, Pham TH, Booty M, Estes JD, Sandler NG, Plass N, Stone DL, Turner ML, Hill S, Butman JA, Schneider R, Babyn P, El-Shanti HI, Pope E, Barron K, Bing X, Laurence A, Lee CC, Chapelle D, Clarke Gl, Ohson K, Nicholson M, et al: An autoinflammatory disease with deficiency of the interleukin-1-receptor antagonist. N Engl J Med 2009, 360(23):2426-2437

13. Lachmann HJ, Lowe P, Felix SD, Rordorf C, Leslie K, Madhoo S, Wittkowski H, Bek S, Hartmann N, Bosset S, Hawkins PN, Jung T: In vivo regulation of interleukin 1 beta in patients with cryopyrin-associated periodic syndromes. J Exp Med 2009, 206(5):1029-1036.

14. Pascual V, Allantaz F, Arce E, Punaro M, Banchereau J: Role of interleukin-1 (IL-1) in the pathogenesis of systemic onset juvenile idiopathic arthritis and clinical response to IL-1 blockade. J Exp Med 2005, 201(9):1479-1486.

15. Colina M, Pizzirani C, Khodeir M, Falzoni S, Bruschi M, Trotta F, Di Virgilio F: Dysregulation of P2X7 receptor-inflammasome axis in SAPHO syndrome: successful treatment with anakinra. Rheumatology (Oxford) 2010, 49(7):1416-1418

16. Herlin T, Fiirgaard B, Bjerre M, Kerndrup G, Hasle H, Bing X, Ferguson PJ: Efficacy of anti-IL-1 treatment in majeed syndrome. Ann Rheum Dis 2013, 72:410-413.

17. Eleftheriou D, Gerschman T, Sebire N, Woo P, Pilkington CA, Brogan PA: Biologic therapy in refractory chronic non-bacterial osteomyelitis of childhood. Rheumatology (Oxford) 2010, 49:1505-1512.

18. Hoffman HM, Rosengren S, Boyle DL, Cho JY, Nayar J, Mueller JL, Anderson JP, Wanderer AA, Firestein GS: Prevention of cold-associated acute inflammation in familial cold autoinflammatory syndrome by interleukin-1 receptor antagonist. Lancet 2004, 364:1779-1785.

19. Grol MW, Panupinthu N, Korcok J, Sims SM, Dixon SJ: Expression, signaling, and function of p2x7 receptors in bone. Purinergic Signal 2009, 5:205-221.

20. Okahashi N, Koide M, Jimi E, Suda T, Nishihara T: Caspases (interleukin-1 beta-converting enzyme family proteases) are involved in the regulation of the survival of osteoclasts. Bone 1998, 23:33-41.

21. Yao Z, Xing L, Qin C, Schwarz EM, Boyce BF: Osteoclast precursor interaction with bone matrix induces osteoclast formation directly by an interleukin-1-mediated autocrine mechanism. J Biol Chem 2008, 283:9917-9924.

22. Vuorikoski: Transcription profiling of human osteoclasts, dendritic cells, macrophages and endothelial cells derived from CD14+ peripheral blood mononuclear cells. 2006. Available on line: http://www.ebi.ac.uk/ microarray-as/ae/browse.html?keywords=E-MEXP-916. In. 2006/11/22 ed.

doi:10.1186/1546-0096-12-30

Cite this article as: Scianaro et al:: Deregulation of the IL-1 $\beta$ axis in chronic recurrent multifocal osteomyelitis. Pediatric Rheumatology 2014 12:30.

\section{Submit your next manuscript to BioMed Central and take full advantage of:}

- Convenient online submission

- Thorough peer review

- No space constraints or color figure charges

- Immediate publication on acceptance

- Inclusion in PubMed, CAS, Scopus and Google Scholar

- Research which is freely available for redistribution

Submit your manuscript at www.biomedcentral.com/submit 